\title{
DBP FORMATION AND SPECIATION IN A CENTRAL ANATOLIAN DAM WATER DEPENDING ON pH, TOC LEVEL, FRACTION AND CHLORINE DOSE
}

\author{
KUCUKCONGAR S. * \\ SEVIMLI M.F. \\ YEL E.
}

Received: 06/06/13

Accepted: 10/06/13

\author{
Selcuk University, Environmental Engineering Department, \\ 42075, Konya, Turkey
}

\begin{abstract}
The effects of $\mathrm{pH}$, NOM concentration, fractions and the chlorine dose on the formation and speciation of THMs and HAAs were determined in Altinapa Dam water (Konya/Turkey). Water sample was isolated and chlorinated at different TOC levels and pH's. The isolate was fractioned; THM and HAA species were measured after chlorination. THM increased with increasing $\mathrm{pH}$ (6 to 8) whereas a consistent $\mathrm{pH}$ tendency could not be inferred from the HAA changes. $\mathrm{CF}$ is the dominant THM specie which exerts up to $91 \%$ of the total THM. The majority of total HAAs composed of MCAA, DCAA and TCAA. The hydrophobic fraction was the main THM precursor under the studied conditions although their percentage was lower than hydrophilics, whereas, hydrophilic fraction had significant contribution to HAA formation, in contrast to the general tendency for HAA. High correlation (0.97) was calculated between total THMs and HAAs.
\end{abstract}

KEYWORDS: Natural organic matter, fractionation, trihalomethanes, haloacetic acids, chlorination.

\section{INTRODUCTION}

Natural organic matter (NOM) exists in all surface waters and groundwaters as a result of complex biotic and abiotic reactions. The application of disinfectants to drinking water reduces the microbial risk but possess chemical risk in the form of disinfection by-products (DBPs) by reactions between dissolved portion of NOM and disinfectant. Applied chlorine rapidly hydrolyses and so formed hypochlorous acid $(\mathrm{HOCl})$ undergoes subsequent reactions resulting in the formation of DBPs. There has been an increasing concern about DBPs since Rook (1974) and Bellar and Lichtenberg (1974). Although there are various identified halogenated DBPs, trihalomethanes (THMs) and haloacetic acids (HAAs) are the most common DBPs which are carcinogenic and potentially hazardous to human health. There are a lot of limitations imposed by EPA, EU and WHO for DBPs. Maximum limits has been decreased in recent revisions.

DBP's distribution depends upon several factors such as chlorine dose, temperature, reaction time, bromide concentration, $\mathrm{pH}$, regional water quality i.e. quantity and characteristics of NOM, and SUVA (Amy et al., 1987; Reckhow et al., 1990; Kitis, 2001; Liu et al., 2011). Increase of chlorine dose has been reported to have positive influence of DBPs yield. Some NOM components react with aqueous chlorine at a much faster rate than others (Harrington et al., 1996). Therefore chlorine dose and contact time are also important variables affecting the yields of DBPs. $\mathrm{pH}$ is an important factor in the interaction between NOM and chlorine. It influences electron distribution within NOM structures and distribution of aqueous chlorine species (Harrington et al., 1996). Several researchers had reported that as $\mathrm{pH}$ increases relative production of THMs increases, trihaloacetic acid formation decreases, and dihaloacetic acid formation is relatively insensitive to $\mathrm{pH}$ (Singer, 1999; Croue et al., 2000; Kim et al., 2002). Krasner et al. (1989) selected 35 water treatment facilities in USA to provide a broad range of source water qualities and treatment process and analyzed THMs, HAAs, formaldehyde, acetaldehyde and cyanogen chloride. They identified that, DBPs that can be expected in drinking water as a function of source water quality, seasonal factors, selection of water treatment process, operation and disinfection processes and chemicals. Liu et al. (2011) 
investigated eight drinking waters and source waters in China and showed that the highest THM concentrations were detected in spring. Yoon et al. (2003) investigated the characteristics of THM formation in major river waters in Korea and suggested that a large variation of trihalomethanes formation potential (THMFP) level may exist over different geographic regions. Nikolaou et al. (2004c) investigated reaction kinetics of a number of DBPs detected in chlorinated surface waters from three different sources and suggested that different speciation of DBPs and different formation rates were observed for different water quality regarding bromide ion presence and organic matter content. Zhang et al. (2011) investigated THMFP and HAAFP in 13 source waters taken from China and this study showed that the organic compounds in different source waters exhibited different reactivities with chlorine. The literature indicated that not only are chlorination conditions important in controlling the production and distribution of the DBPs but also the origin and nature of the NOM plays an important role. SUVA is generally accepted as a good surrogate parameter for the aromatic character of NOM. Croue et al. (2000) supported the importance of aromaticity in the production of chlorinated DBPs.

It can be inferred from the literature that the raw water characteristics affect the DBP formation but they are not the only effect. Similarly, the fractional distribution of the NOM is not the unique effect either. From this point, each water resource is another literature, depending on its characteristics. There are not published studies on THM and HAA levels of water resources in Central Anatolian region, a dry climate with high agricultural activities, a detailed study indicating the contribution of NOM fractions to THM, HAA levels and the effects of $\mathrm{pH}, \mathrm{TOC}$ and chlorine dosage for the waters of this quality is lacked. Therefore, in this study, NOM was isolated from a surface water resource in Central Anatolian region, The isolate was fractionated by resin adsorption chromatography (RAC) to indicate THMs and HAAs formation at varying TOC, $\mathrm{pH}$ and chlorine dosage, and to indicate the contribution of hydrophobic and hydrophilic fractions on the formation of THMs and HAAs for such a water resource by comparing the results with the literature.

\section{MATERIALS AND METHODS \\ Water sample}

Water sample was supplied from a dam, which has been used for the domestic and industrial water supply purposes in Konya city in central Anatolian in Turkey. The characteristics of the water are presented in Table 1.

Table 1. Water Sample Characteristics

\begin{tabular}{cc}
\hline Parameter & Value \\
\hline TOC, $\mathrm{mg} \mathrm{I}^{-1}$ & 2.48 \\
$\mathrm{pH}$ & 7.20 \\
Conductivity, $\mu \mathrm{cm}^{-1}$ & 367 \\
Turbidity, NTU & 5.48 \\
$\mathrm{Br}^{-}, \mu \mathrm{I} \mathrm{I}^{-1}$ & $<20$ \\
$\mathrm{UV}_{254}, 1 \mathrm{~cm}^{-1}$ & 0.035 \\
$\mathrm{SUVA}_{254}, \mathrm{I} \mathrm{mg}^{-1} \cdot \mathrm{m}$ & 1.41 \\
\hline
\end{tabular}

\section{Experimental \\ Isolation}

All the dissolved organics and inorganics in the water sample were isolated using a laboratory scale reverse osmosis membrane (Filmtec, DOW Chemical Company, USA) which is composed of thin film composite membranes packed in a spiral wound configuration. The isolate was kept in the dark at $+4^{0} \mathrm{C}$ in a refrigerator throughout the studies.

\section{Fractionation and chlorination}

The fractionation of isolate NOM was carried out using resin fractionation procedure based on Leenheer (1981) and Thurman and Malcolm (1981) with some modification (Swietlik et al., 2004). Supelite DAX-8 resin (Supelco, USA), Duolite A-7 anion exchange resin (Aldrich, Germany) and AGMP-50 cation-exchange resin (Bio-Rad, USA) were used for fractionation of NOM. All resins were purified by Soxhlet extraction before the experimental studies. All columns were constructed of glass, connecting tubing was glass and peristaltic pumps (Heidolph, Germany) equipped with 
Pharmed pump tubing with minimum $0.3 \mathrm{ml} \mathrm{min}^{-1}$ of flow rates is suitable for pumping water samples through the columns. Columns were conditioned as described by Leenheer (1981).

The water isolate was pumped through the XAD-8 column at $1.0 \mathrm{ml} \mathrm{min}^{-1} \mathrm{flow}$ rate. The resin and isolate volumes were determined depending on the TOC of the input solution. Hydrophobic base fraction was eluted from column by $\mathrm{HCl}$ flow. Effluent of column was acidified with $\mathrm{HCl}$ to adjust the $\mathrm{pH}$ to 2 and recycled through the column. Hydrophobic acid fraction was eluted from column by $\mathrm{NaOH}$. After that XAD-8 resin was dried and Soxhlet-extracted with methanol. This extraction procedure was for the hydrophobic neutral fraction. The sample which contains only hydrophilic solutes, was pumped to AG-MP-50 column. Hydrophilic base fraction was eluted from column by $\mathrm{NH}_{4} \mathrm{OH}$. After this elution, the sample containing only hydrophilic acid and neutral fractions, was pumped to Duolite A-7 column and hydrophilic acid fraction was eluted from column by $\mathrm{NH}_{4} \mathrm{OH}$. The resin effluent was collected as hydrophilic neutral fraction.

The selected experimental variables of the study were TOC level, environment $\mathrm{pH}$ and chlorine dosage. The effects of TOC were studied in 2, 3 and $4 \mathrm{mg} \mathrm{I}^{-1}$ initial TOC levels, and for each of this $\mathrm{pH} 6,7.2$ and 8 were tried. $0.01 \mathrm{M}$ phosphate buffer solution was used for maintaining the $\mathrm{pH}$ constant during the 24 hours incubation time. Five chlorine dosages between 1.4 to $4.2 \mathrm{mg} \mathrm{I}^{-1}$ were applied.

The isolates were diluted with ultrapure water (Human Corp., Korea) to adjust the TOC concentrations and after $\mathrm{pH}$ adjustment each was chlorinated with proper dosages according to UFC protocol (Summers et al., 1996). Stock chlorine solution was prepared from sodium hypochlorite (Merck, Germany) including 6-14\% free chlorine. After the chlorination, each amber bottle containing the $125 \mathrm{~mL}$ volume of water sample was closed with a cap equipped with a Teflon septa. Bottle was left for incubation for a desired time in the dark providing the reaction between chlorine and organic matter. After the incubation period, residual chlorine was measured and then quenched with sodium sulfite prior to analysis for DBPs.

\section{Analyses}

The chlorine was measured by the DPD colorimetric method (APHA 2005). TOC analysis was performed by the high-temperature combustion method (APHA 2005) using a TOC- $\mathrm{V}_{\mathrm{CPH}}$ model TOC analyzer by Shimadzu, Japan.

THM and HAA analyses were carried out according to EPA Method 551.1 (EPA 1995) and 552.3 (EPA 2003), respectively. GC measurements were performed on an Agilent model $6890 \mathrm{GC}$ equipped with Agilent 7683 autosampler, $\mu$-electron capture detector (ECD) and HP-5MS capillary column (Agilent J\&W Scientific, $30 \mathrm{~m}$ length, $0.25 \mathrm{~mm}$ i.d. and $0.25 \mu \mathrm{m}$ film thickness, USA). The system was operated at splitless injection mode. Injector temperature was $200^{\circ} \mathrm{C}$, detector temperature was $290^{\circ} \mathrm{C}$. High purity helium $\left(2.2 \mathrm{ml} \mathrm{min}^{-1}\right.$ for THM, $1.8 \mathrm{ml} \mathrm{min}^{-1}$ for HAA) was used as the carrier gas and high purity nitrogen $\left(28.9 \mathrm{ml} \mathrm{min}^{-1}\right.$ for THM, $35.0 \mathrm{ml} \mathrm{min}^{-1}$ for HAA) was used as the make-up gas. THM temperature program was as follows: $35^{\circ} \mathrm{C}$ for $22 \mathrm{~min}, 10^{\circ} \mathrm{C} \mathrm{min}^{-1}$ up to $125^{\circ} \mathrm{C}$ and HAA temperature program was $35^{\circ} \mathrm{C}$ for $10 \mathrm{~min}, 5^{\circ} \mathrm{C} \min ^{-1}$ up to $75^{\circ} \mathrm{C}$ for $15 \mathrm{~min}, 5^{\circ} \mathrm{C} \min ^{-1}$ up to $100^{\circ} \mathrm{C}$ for $5 \mathrm{~min}, 5^{\circ} \mathrm{C} \mathrm{min}^{-1}$ up to $135^{\circ} \mathrm{C}$ for $2 \mathrm{~min}$. Injection volumes were 1 and $2 \mu \mathrm{L}$ for THM and HAA, respectively.

THM calibration curves, obtained with standards from Supelco, USA, had at least seven points for four THM species; chloroform (CF), bromodichloromethane (BDCM), chlorodibromomethane (DBCM), bromoform (BF) with detection limits of $0.15,0.01$ and $0.10 \mathrm{ppb}$, respectively.

HAA calibration curves were obtained with standards from AccuStandard, USA and had at least five points and nine HAA species; monochloroacetic acid (MCAA), monobromoacetic acid (MBAA), dichloroacetic acid (DCAA), trichloroacetic acid (TCAA), bromochloroacetic acid (BCAA), dibromoacetic acid (DBAA), bromodichloroacetic acid (BDCAA), chlorodibromoacetic acid (CDBAA) and tribromoacetic acid (TBAA). Detection limits of MCAA, DCAA, TCAA, BCAA, DBAA, BDCAA were $1.00,0.30,3.90,0.04,0.01,0.12 \mathrm{ppb}$, respectively.

\section{RESULTS AND DISCUSSION}

Experimental studies have been performed in two stages; fractional distribution of natural organic matter of water sample, THM and HAA formations depending on TOC level, $\mathrm{pH}$ and chlorine dosage. 


\section{Fractional distribution}

Fractional distribution of organic matter of dam water was determined by the procedures explained above and given in Table 2. Hydrophobic and hydrophilic compounds of organic matter were found as 45.1 and $52.4 \%$ respectively. It was reported that hydrophobic components are in the range of 34-76 \% in natural waters (Day et al., 1991; Croue et al., 1993; Leenheer, 1981). Base fraction of hydrophilic and hydrophobic portion has the least percentage while neutral fractions occupy the highest portion. Hydrophobic NOM extracts with a narrow range of aromatic carbon content (21$33 \%$ ) were reported as the important in DBP formation (Harrington et al., 1996). Hydrophobic neutral fraction is the highest portion of hydrophobics and the second highest portion of all fractions. Hydrophobic acid has the characteristic of soil fulvic and composed of high and medium molecular weight alkyl monocarboxylic acids, dicarboxylic acids, aromatic acids, as well as tannins and phenols. Fulvic acid yields a good correlation between DBP formation and phenolic carbon content. For most of the natural waters, hydrophobic acids were reported as to have relatively low concentration to other NOM fractions. Hydrophobic base fraction is the lowest fraction in this study. Hydrophilic neutral fraction is known as the least problemmatic DBP precursor among the fractions. It occupies the highest percentage in the water sample of this study. Hydrophilic acid fraction involves hydroxyl acid groups, mono- and di- carboxylic acids, sulphonic acids (Leenheer, 1981). Hydrophilic base fraction includes proteinaceous materials like amino acids, amino sugars, purines, pyridins, and pyrimidines.

Table 2. Fractional Distribution for the Isolate

\begin{tabular}{llll}
\hline Fractions & $\%$ & \% Range & \\
\hline Hydrophobic neutral & 22.7 & $0-25$ & \\
Hydrophobic acid & 16.5 & $19-68$ & Total Hydrophobic \\
Hydrophobic base & 5.9 & $0-22$ & $45.1 \%$ \\
Hydrophilic neutral & 29.7 & $1-35$ & \\
Hydrophilic acid & 15.6 & $8-50$ & Total Hydrophilic \\
Hydrophilic base & 7.1 & $5-10$ & $52.4 \%$ \\
\hline Total & 97.5 & & \\
\hline
\end{tabular}

\section{THM formation}

\section{The effects of time, initial TOC and pH on THM species}

THM formation started rapidly and more than $50 \%$ of the total THMs formed within the first 2 hours in chlorinated samples and then decelerated and continued until 24 hours (Figure $1 a, b$ and $c$ ). Totally 48 hours contact time was followed for DBPs but, as negligible difference after 24 hour was observed. The highest THM level was $161 \mathrm{\mu g} \mathrm{I}^{-1}$ at $4 \mathrm{mg} \mathrm{I}^{-1}$ initial TOC and pH 8 while the lowest was $62 \mathrm{mg} \mathrm{l}^{-1}$ at $2 \mathrm{mg} \mathrm{l}^{-1}$ initial TOC and $\mathrm{pH}$. The total THM increased with increasing initial TOC level as expected.

Comparison of the THM concentrations at the end of 24 hours in Figure 1d indicates increase in THMs with increasing pH. At $4 \mathrm{mg} \mathrm{l}^{-1}$ initial TOC, total THM levels increased from 135 to $161 \mathrm{\mu g} \mathrm{l}^{-1}$ at $\mathrm{pH} 6$ to 8 . Effects of $\mathrm{pH}$ on DBP formation had studied in the range of 4 to 9 in the literature and these indicated the increase of THM above pH 7 (Xie 2004; Uyak et al., 2007). The increase in CF formation at high $\mathrm{pH}$ is associated with the base-catalyzed haloform-type reaction (Miller and Uden, 1983). THMs increase as the $\mathrm{pH}$ is alkalized, due to the fact that CF formation increases as the concentration of $\mathrm{OH}$ ion in the solution increases, as the solubility of humic acid increases and it has a broad molecule surface in a water solution. CF is the dominant specie of all THMs which exerts about $49-91 \%$ of the total THM depending upon the TOC and $\mathrm{pH}$. As depicted in the literature (Ates et al., 2007), increasing initial TOC generated higher quantity of CF. Of all studied pHs, the highest CF concentrations were observed at $\mathrm{pH} 8$ whereas $\mathrm{pH}$ dependency between $\mathrm{pH} 6$ to 7.2 was more sensitive at TOC $2 \mathrm{mg} \mathrm{I}^{-1}$. In all conditions BF remained below detection limit to the low $\mathrm{Br}^{-}$ concentration of the dam water sample.

When the total hydrophilic fraction was chlorinated, CF did not form, BDCM was the most abundant THM by occupying the $55 \%$ of THM species. Therefore the hydrophobic fraction was the main THM precursor under these conditions although their percentage was lower than hydrophilics. The more hydrophobic and more acidic fractions provide the most active precursor sites (larger DBP formation 
potentials). A significiant number of studies (Reckhow and Singer 1990; Harrington et.al., 1996; Pomes et.al., 1999; Gallard and Gunten, 2002; Page et al., 2002; White et.al., 2003; Nikolaou et.al., 2004b) have shown that humic and fulvic acids (i.e., hydrophobic acids) isolated from natural waters are highly reactive with chlorine and precursors for DBPs. On the other hand, aminoacid structures in the hydrophilic base fraction and beta-hydroxy acids and beta-ketones that might be predominant in neutral and hydrophilic acid fractions are known as to be THM precursors. Hydrophilic acid fractions were addressed in THM formation by Marhaba and Van (2000). Moreover, Hwang et al., (2000), whose TOC, SUVA and fractional distribution were consistent with this study, suggested that the highest yield of THMs was from the hydrophilic acid and neutral fraction.

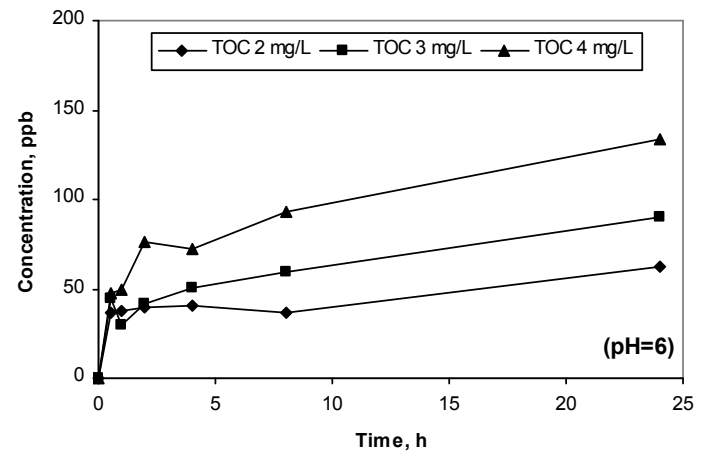

(a)

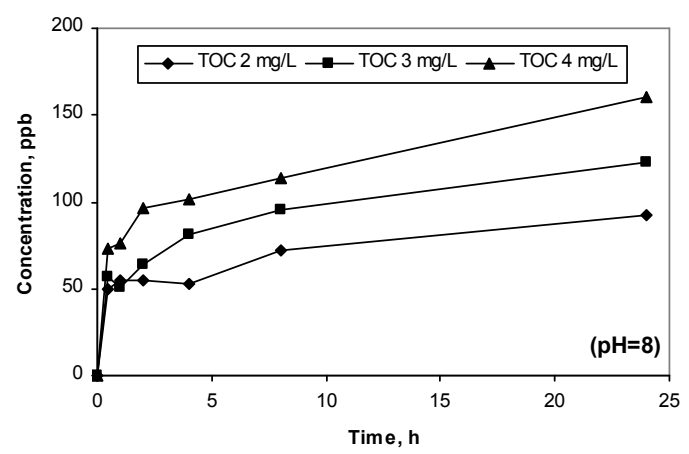

(c)

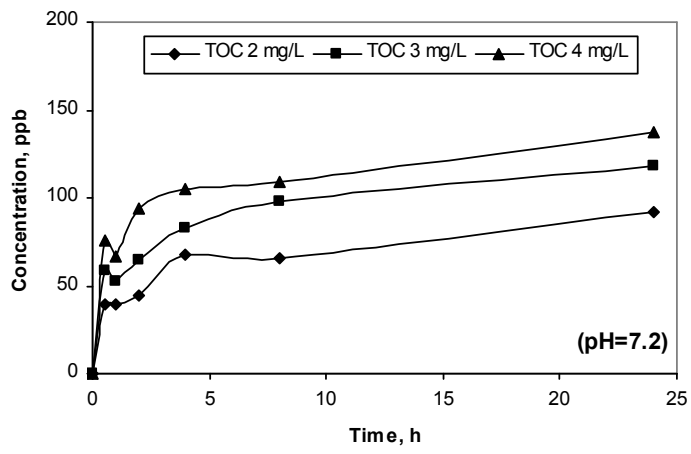

(b)

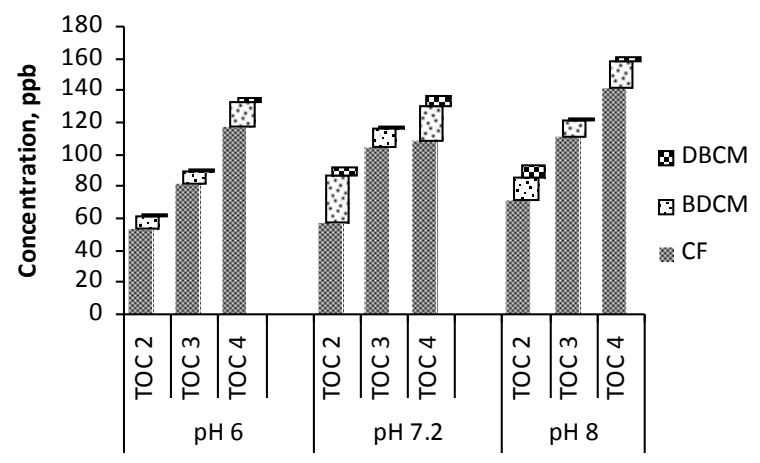

(d)

Figure 1. Change of THM with time at (a) $\mathrm{pH}=6$, (b) $\mathrm{pH}=7.2$, (c) $\mathrm{pH}=8$; and (d) distribution of THM species under varying $\mathrm{pH}$ and $\mathrm{TOC}$ conditions

\section{The effect of chlorine dosage on THM species}

Studies were performed to obtain the effect of chlorine dose on the formation of THMs at $\mathrm{pH} 7.2$ and $2 \mathrm{mg} \mathrm{l}^{-1}$ of TOC. As chlorine dosage was increased from 1.4 to $4.2 \mathrm{mg} \mathrm{l}^{-1}$, the 24 hours total THMs increased (Figure 2). In the figure, $\mathrm{C}$ shows the 24 hours total THM concentration of each chlorine dose applied between 1.4 to $4.2 \mathrm{mg} \mathrm{l}^{-1}$ and $\mathrm{C}_{\mathrm{UFC}}$ shows the 24 hours THM concentration of chlorine dose given the $1.0 \pm 0.4 \mathrm{mg} \mathrm{I}^{-1}$ residual chlorine. The change in total THM was directed by CF and BDCM, which were the most abundant species. At low chlorine doses, substitution product dominates, where chlorine incorporates into the organic matter. At higher doses, oxidation and cleavage products dominate, and precursor material could be completely oxidized (Johnson and Jensen, 1986). Higher chlorine doses lead to higher DBP formation and conversion of the intermediate species to final products (Nikolaou et al., 2004a; Xie, 2004). The least common species, mainly bromine containing species, were not affected from chlorine dosage because of constant and low bromine levels in the sample water. BDCM was observed at very low levels and not change with increasing chlorine dosage. 


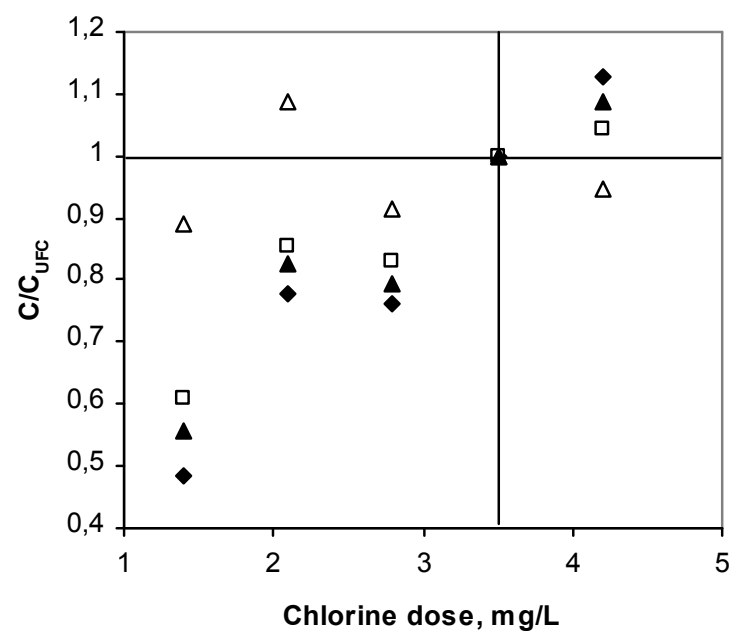

Figure 2. Change of concentration of THM compounds with chlorine dosage (TOC:2 $\left.\mathrm{mg} \mathrm{I}^{-1}, \mathrm{pH}: 7.2\right)$. - CF $\square$ BDCM $\triangle \mathrm{DBCM} \triangle$ Total

\section{HAA formation}

\section{The effects of time, initial TOC and pH on HAA species}

HAA formations were observed at TOC 2, 3 and $4 \mathrm{mg} \mathrm{l}^{-1}$ and $\mathrm{pH} 6,7.2,8$ (Figure 3a, $\mathrm{b}$ and c). Total HAA generally increased with increasing initial TOC since the chlorine demand increased (Xie 2004). Initial organic matter content has direct influence on DBP formation. 61-95\% of total HAA formation had completed in the first 2 hours reaction time and remained nearly constant until the end of 24 hours. The lowest HAA concentration was achieved at $\mathrm{pH} 6$, TOC $2 \mathrm{mg} / \mathrm{L}$ as $324 \mathrm{\mu g} \mathrm{I}^{-1}$ while the highest was at $\mathrm{pH} 8$, TOC $4 \mathrm{mg} \mathrm{I}^{-1}$ as $670 \mathrm{\mu g} \mathrm{I}^{-1}$.

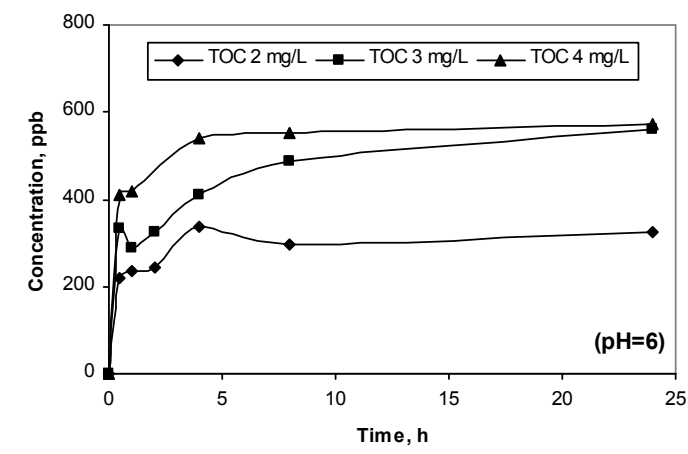

(a)

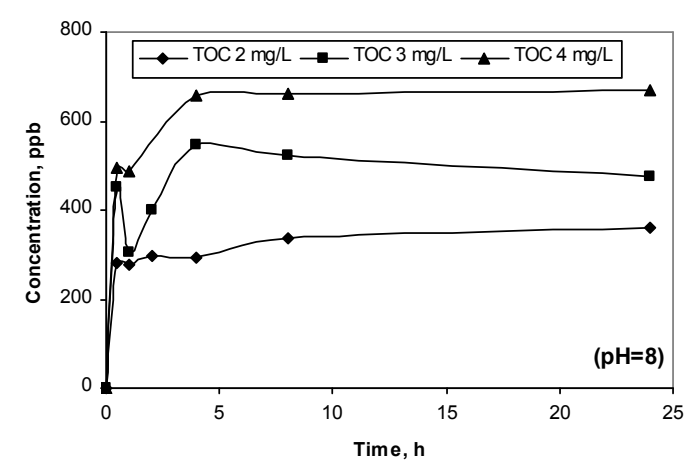

(c)

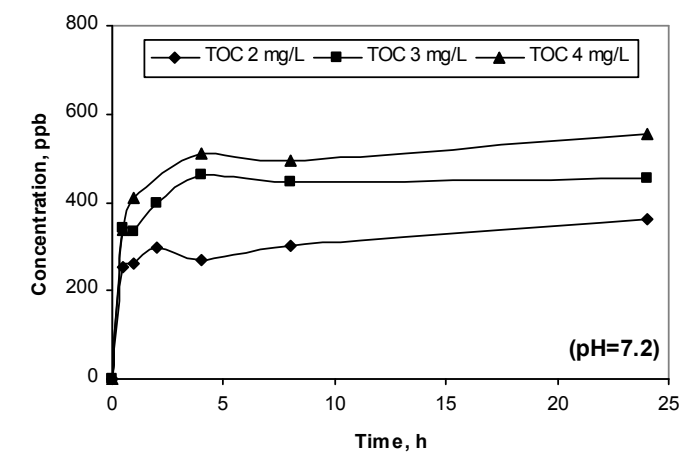

(b)

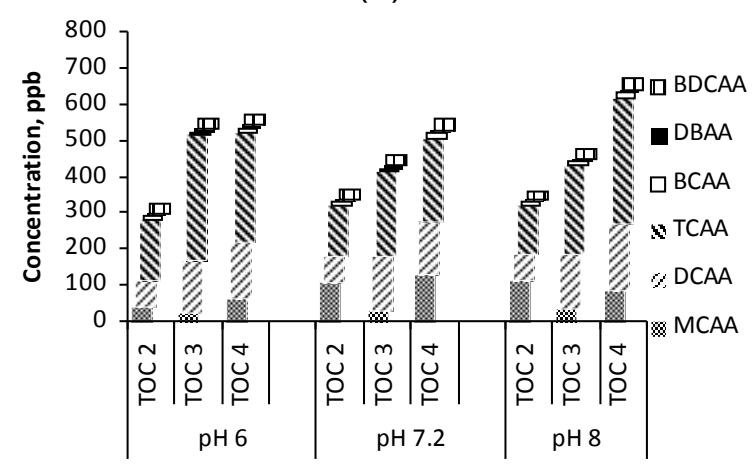

(d)

Figure 3. Change of HAA with time at (a) $\mathrm{pH}=6$, (b) $\mathrm{pH}=7.2$, (c) $\mathrm{pH}=8$; and

(d) distribution of HAA species under varying $\mathrm{pH}$ and TOC conditions

HAA species at the end of 24 hours are given in Figure $3 \mathrm{~d}$. The majority of total HAAs composed of MCAA, DCAA and TCAA. DCAA and the other least common species are not highly affected from 
$\mathrm{pH}$. However, in 6-8 $\mathrm{pH}$ interval changes of MCAA and TCAA with $\mathrm{pH}$ were almost the opposite. While MCAA was increasing, TCAA was decreasing or vice versa. These two species direct the total HAA profiles. In all conditions MBAA, CDBAA and TBAA remained below detection limits. HAA species containing bromine were either below detection limits or at very low concentrations. The influence of $\mathrm{pH}$ on HAA formation is complicated. MCAA reached its highest values at $\mathrm{pH}$ around 7 . $\mathrm{pH}$ does not have big impacts on BCAA formation (Uyak et al., 2007). Miller and Uden (1983) suggested that formation of TCAA involves a much more rigorous chlorination-oxidation step than does formation of THMs and that the decrease of TCAA formation with increasing $\mathrm{pH}$ is related to the deprotonation of hypochlorous acid. Oxidation rates of different species change with $\mathrm{pH}$ (Reckhow et al., 1990). Formation of TCAA is the same at pH 5 to 7 and decreases at higher pH (Pourmoghaddas et al., 1993), whereas DCAA increases slightly with decreasing pH (Miller and Uden 1983).

The distribution of HAA species after chlorination of hydrophilic fraction was consistent with the distribution after chlorination of isolate. As a result of chlorination of total hydrophilics, $55 \%$ of total HAA was TCAA which was followed by DCAA (31\%). Therefore, unlike THMs, hydrophilic fraction has significant contribution to HAA formation, although hydrophobic neutral fractions were mostly reported as effective fraction for HAA formation in the literature (Marhaba and Van, 2000). Hwang et al., (2000) stated that the hydrophilic acid and neutral, and hydrophilic base fractions had the highest HAA yields. The reactivity of individual fractions to form DBPs provided some insight into the nature of NOM (Hwang et al., 2000), for example, the predominance of DCAA over TCAA for NOM fractions suggests that the water sample NOM has a higher proportion of hydroxyl groups rather than oxidizable functional groups, or vice versa. Hydrophilic NOM fractions enriched in nitrogenous type structures were found to exert a strong chlorine demand associated with high DCAA production (Croue et al., 2000). The results demonstrate that not only humic substances but also the more hydrophilic NOM (i.e., nonhumic substances) play an important role for the production of DBPs upon chlorination.

\section{The effect of chlorine dosage on HAA species}

As chlorine dosage was increased from 1.4 to $4.2 \mathrm{mg} \mathrm{l}^{-1}$, the 24 hours total HAAs increased (Figure 4). DBAA and BDCAA were observed at very low levels and not change with increasing chlorine dosage. The change in total HAA was directed by TCAA, MCAA and DCAA, which were at highest level as well. At low chlorine doses, substitution product dominates, where chlorine incorporates into the organic matter. At higher doses, oxidation and cleavage products dominate, and precursor material could be completely oxidized (Johnson and Jensen 1986). Higher chlorine doses lead to higher DBP formation and conversion of the intermediate species to final products (Nikolaou et al., 2004a; Xie, 2004).

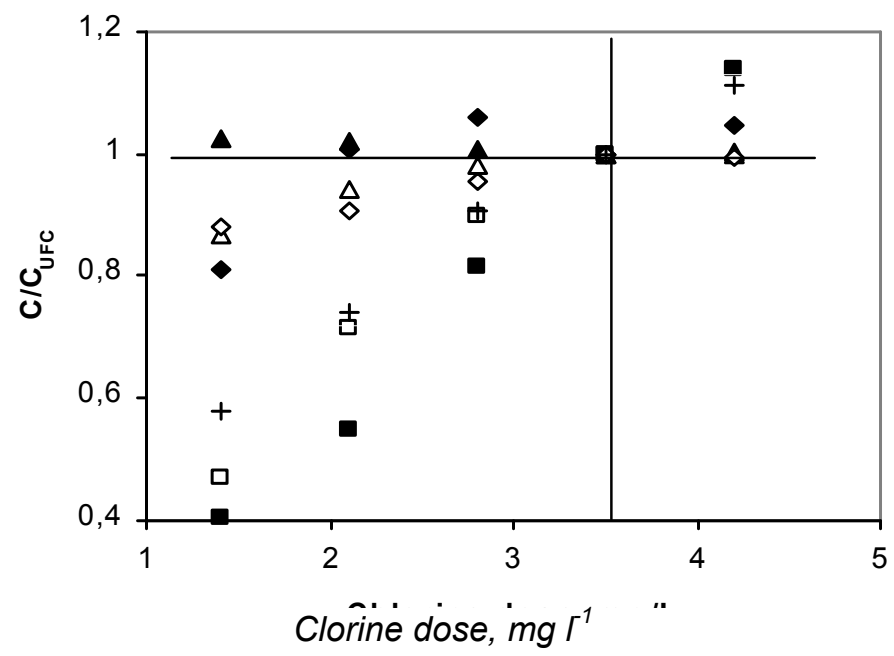

Figure 4. Change of concentration of HAA compounds with chlorine dosage (TOC: $2 \mathrm{mg} \mathrm{l}^{-1}, \mathrm{pH}$ : 7.2). MCAA $\square$ DCAA $\triangle$ BCAA $\backsim$ TCAA $\triangle$ DBAA $\diamond B D C A A+$ Total 


\section{THMs-HAAs correlation}

Water sample was investigated for the association of THM and HAA compounds, based on the data set in which both THM and HAA concentrations were available. Correlation between total THM and HAA was examined (Figure 5) through simple linear regression analysis introducing total THM levels as the independent variable, and total HAA level as the dependent variable. There were some studies indicating good correlations between THMs and HAAs (Villanueva et al., 2003; Serodes et al., 2003; Ates et al., 2007) as well as studies presuming that THMs were not good indicators of HAAs (Malliarou et al., 2005). It is obvious that to be able to make such an inference, the $\mathrm{pH}$ and initial compositions should be considered separately. Correlation coefficient $(r)$ was calculated as 0.97 for this relationship. This good correlation was previously found as 0.92 for 29 different dam waters by Ates et al., (2007).

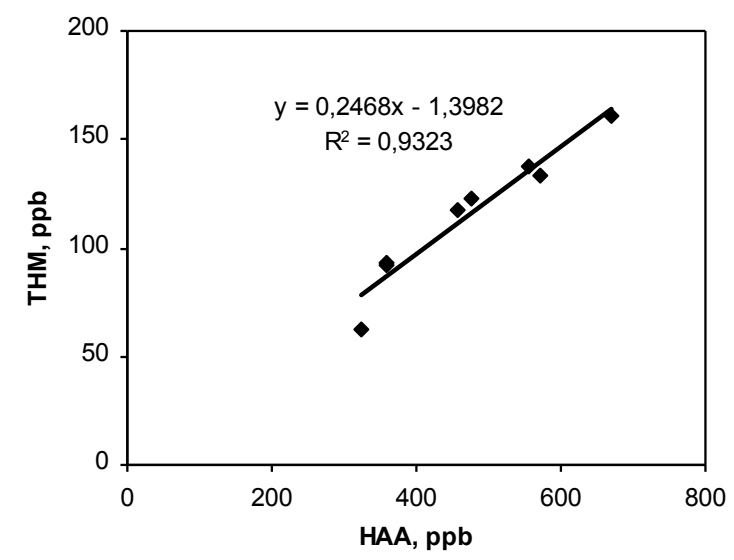

Figure 5. The relationship between THMs and HAAs

\section{CONCLUSION}

The main conclusions were as follows:

- Hydrophobic and hydrophilic compounds of organic matter were found as 45.1 and $52.4 \%$, respectively, in Altinapa Dam Water (Central Anatolia Region).

- The DBP formation starts rapidly just after chlorination, the majority of the THMs and HAAs form in the first 2 hours and their concentrations reach the ultimate value in 24 hours.

- $\mathrm{CF}$ is the dominant specie of all THMs.

- The majority of total HAAs composed of MCAA, DCAA and TCAA.

- MCAA and TCAA direct the total HAA profiles. Between pH 6 and 8, changes of them with $\mathrm{pH}$ were almost the opposite. From $\mathrm{pH} 6$ to 8 while MCAA was increasing, TCAA was decreasing or vice versa.

- The hydrophobic fraction was the main THM precursor under the studied conditions although their percentage was lower than hydrophilics.

- Unlike THMs, hydrophilic fraction has significant contribution to HAA formation, although hydrophobic neutral fractions were mostly reported as effective fraction for HAA formation in the literature

- Correlation between total THMs and HAAs was high.

- Increasing the chlorine dose should lead the higher concentration of THMs and HAAs. The change in total THM and HAA levels were directed by the changes in the most abundant species in the system.

\section{ACKNOWLEDGEMENTS}

This study is financially supported by TUBITAK under grant no 1041123 and Selcuk University Scientific Research Projects Coordinating Office under grant no 05101022. 


\section{REFERENCES}

Aiken G., Leenheer J.A. (1993) Isolation and chemical characterization of dissolved and colloidal organic matter, Chemistry and Ecology, 8, 135-151.

Amy G.L., Chadik P.A. and Chowdhury Z.K., (1987) Developing models for predicting trihalomethane formation potential and kinetics, J. Am Water Work Ass., 79, 89-97.

Standard Methods for the Examination of Water and Wastewater (2005) 21th edn, American Public Health Association/American Water Works Association/Water Environment Federation, Washington DC, USA.

Ates N., Kaplan S.S., Sahinkaya E., Kitis M., Dilek F.B. and Yetis U. (2007) Occurence of disinfection byproducts in low DOC surface waters in Turkey, J. Hazard Mater., 142, 526-534.

Bellar T.A. and Lichtenberg J.J. (1974) Determining volatile organics at microgram-per-liter levels by gas chromatography, J. Am Water Work Ass., 66, 739-744.

Croue J.P., Martin B., Simon P. and Legube B. (1993) Les matieres hydrophobes et hydrophiles des eaux de retenue- extraction, caracterisation et quantification, Water Supply, 11, 79-90.

Croue J.P., Violleau D. and Labouyrie L. (2000) Disinfection by-product formation potentials of hydrophobic and hydrophilic natural organic matter fractions: a comparison between a low- and highhumic water. (In S.E. Barrett, S.W. Krasner, G.L. Amy (Eds.), Natural organic matter and disinfection by-products-characterization and control in drinking water, (pp. 139-153). American Chemical Society, Washington, DC).

Day G.M., Beckett R., Hart B. and McKelvie I., (1991) Characterization of natural organic matter from four Victorian freshwater systems, Aust J. Mar Freshwater Res., 42, 675-687.

EPA (1995) Method 551.1 Determination of chlorination disinfection by-products, chlorinated solvents and halogenated pesticides/herbicides in drinking water by liquid-liquid extraction and gas chromatography with electron-capture detection. Office of Research and Development, Ohio.

EPA (2003) Method 552.3 Determination of haloacetic acids and dalapon in drinking water by liquid-liquid microextraction, derivatization and gas chromatography with electron capture detection. Office of Groundwater and Drinking Water, Ohio.

Gallard H. and Gunten U (2002) Chlorination of natural organic matter: kinetics of chlorination and of THM formation, Water Res., 36, 65-74.

Harrington G.W., Bruchet A., Rybacki D. and Singer P.C., (1996) Characterization of natural organic matter and its reactivity with chlorine. (In R.A. Minear, G.L. Amy (Eds.), Water disinfection and natural organic matter characterization and control, (pp. 138-158). American Chemical Society, Washington, DC).

Hwang C.J., Sclimenti M.J. and Krasner S.W. (2000) Disinfection by-product formation reactivities of natural organic matter fractions of a low-humic water. (In S.E. Barrett, S.W. Krasner, G.L. Amy (Eds.), Natural organic matter and disinfection by-products-characterization and control in drinking water, (pp. 173-187). American Chemical Society, Washington, DC).

Johnson J.D. and Jensen J.N., (1986) THM and TOX formation: routes, rates and precursors, J Am Water Work Ass., 156.

Kim J., Chung Y., Shin D., Kim M., Lee Y., Lim Y. and Lee D., (2002) Chlorination by-products in surface water treatment process, Desalination, 151, 1-9.

Kitis M., (2001) Probing chlorine reactivity of dissolved organic matter for disinfection by-product (DBP) formation: relations with specific ultraviolet absorbance (SUVA) and development of the DBP reactivity profile. $\mathrm{PhD}$ Thesis, Clemson University.

Korshin G.V., Benjamin M.M. and Sletten R.S. (1997) Adsorption of natural organic matter (NOM) on iron oxide: effects on NOM composition and formation of organo-halide compounds during chlorination, Wat Res., 31, 1643-1650.

Leenheer J.A. (1981) Comprehensive approach to preparative isolation and fractionation of dissolved organic carbon from natural waters and wastewaters, Environmental Science \& Technology, 15 (5): 578-587.

Liu S.G., Zhu Z.L., Qiu Y.L. and Zhao J.F. (2011) Effect of ferric and bromide ions on the formation and speciation of disinfection byproducts during chlorination, Journal of Environmental Sciences, 23 (5), 765-772.

Liu W.B., Zhao Y.M., Cho, C.WK. and Wang D.S., (2011) Formation of disinfection byproducts in typical Chinese drinking water, Journal of Environmental Sciences, 23 (6), 897-903

Malliarou E., Collins C., Graham N. and Nieuwenhuijsen M.J., (2005) Haloacetic acids in drinking water in the United Kingdom, Water Res., 39, 2722-2730. 
Marhaba T.F. and Van D. (2000) The variation of mass and disinfection by-product formation potential of dissolved organic matter fractions along a conventional surface water treatment plant, J. Hazard Mater A., 74, 133-147.

Miller J.W. and Uden P.C., (1983) Characterization of nonvolatile aqueous chlorination products of humic substances, Environ Sci Technol., 17 (3), 150-157.

Nikolaou A.D., Lekkas T.D. and Golfinopoulos S.K. (2004a) Kinetics of the formation and decomposition of chlorination by-products in surface waters, Chemical Engineering Journal, 100, 139-148.

Nikolaou A.D., Golfinopoulos S.K., Lekkas T.D. and Kostopoulou M.N. (2004b) DBP levels in chlorinated drinking water: effect of humic substances, Enviromental Monitoring and Assessment, 93, 301-319.

Nikolaou A.D., Golfinopoulos S.K., Arhonditsis G.B., Kolovoyiannis V. and Lekkas T.D. (2004c) Modeling the formation of chlorination by-products in river waters with different quality, Chemosphere, 55, 409420.

Page D.W., Leeuwen J.A., Spark K.M., Drikas M., Withers N. and Mulcahy D.E. (2002) Effect of alum treatment on the trihalomethane formation and bacterial regrowth potential of natural and synthetic waters, Water Res., 36, 4884-4892.

Pomes M.L., Green W.R., Thurman E.M., Orem W.H. and Lerch, H.E. (1999) DBP formation potential of aquatic humic substances, J. Am Water Work Ass., 91 (3), 103-115.

Pourmoghaddas H., Steven A.A., Kinman R.N., Dressman R.C., Moore L.A. and Ireland J.C., (1993) Effect of bromide ion on formation of HAAs during chlorination, J. Am Water Work Ass., 85 (1), 82-87.

Reckhow, D.A. and Singer, P.C., (1990) Chlorination by-products in drinking waters: from formation potentials to finished water concentrations, J Am Water Work Ass., 173-180.

Reckhow D.A., Singer P.C. and Malcolm R.L. (1990) Chlorination of humic materials: by-product formation and chemical interpretations, Environ SciTechnol., 24 (11), 1655-1664.

Rook J.J. (1974) Formation of haloforms during chlorination of natural waters, Water Treatment Examination, 23, 234-243.

Serodes J-B., Rodriguez M.J., Li H. and Bouchard C. (2003) Occurence of THMs and HAAs in experimental chlorinated waters of the Quebec City area (Canada), Chemosphere, 51, 253-263.

Singer P.C. (1999) Humic substances as precursors for potentially harmful disinfection by-products, Water Sci Technol., 40 (9), 25-30.

Summers R.S., Hooper M.S., Shukairy H.M., Solarik G. and Owen, D. (1996) Assessing DBP yield: uniform formation conditions, J. Am Water Work Ass., 88 (6), 80-93.

Swietlik J., Dabrowska A., Raczyk-Stanislawiak U. and Nawrocki J., (2004) Reactivity of natural organic matter fractions with chlorine dioxide and ozone, Water Res., 38, 547-558.

Thurman E.M. and Malcolm R.L., (1981) Preparative isolation of aquatic humic substances, Environmental Science \& Technology, 15 (4), 463-466.

Uyak V., Ozdemir K. and Toroz I., (2007) Multiple linear regression modeling of disinfection by-products formation in Istanbul drinking water reservoirs, Science of the Total Environment, 378, 269-280.

Villanueva C.M., Kogevinasa M. and Grimaltb J.O., (2003) Haloacetic acids and trihalomethanes in finished drinking waters from heterogeneous sources, Water Res., 37, 953-958.

White D.M., Garland D.S., Narr J. and Woolard C.R.,(2003) Natural organic matter and DBP formation potenatial in Alaskan water supplies, Water Res., 37, 939-947.

Xie Y. (2004) Disinfection by-products in drinking water formation, analysis and control. Lewis Publishers, USA.

Yoon J., Choi Y., Cho S. and Lee D. (2003) Low trihalomethane formation in Korean drinking water, The Science of the Total Environment, 302, 157-166.

Zhang J.Z., Yu J.W., An W., Liu J., Wang Y.J., Chen Y.J. et al., (2011) Characterization of disinfection byproduct formation potential in 13 source waters in China, Journal of Environmental Sciences, 23 (2), 183-188 